\title{
ROLES OF PATENTS IN ECONOMIC DEVELOPMENT AND INTEGRATION
}

\author{
Omar Tanane ${ }^{1}$
}

date of paper receipt:

date of sending to review:

date of review receipt:

05.05.2020.

08.05.2020.

16.05.2020.

\section{Review Article}

doi: 10.2478/eoik-2020-0008

UDK: 001.891:330.342.151(100)

${ }^{1}$ Hassan II University of Casablanca, Sciences Faculty of Ben Msik, LPCMA Laboratory, Morocco

\begin{abstract}
In this paper we have worked on a number of documents and articles published to find a relationship between patents and the economic growth of countries. We have found that patents and their applications are important for economic growth. The patent is not always a global indicator of all the technological knowledge produced, since a considerable number of technological know-how remains in the form of business secrets or sometimes the technology is published in scientific articles.

The patent can be an economic policy instrument to encourage investment in research and development. More patents lead to more innovations and vice versa. The patent is a vector of economic growth through the promotion of innovation.
\end{abstract}

Keywords:

Patents; Development; Economies; property; wealth; growth 


\section{INTRODUCTION}

One of the major levers of economic growth is technology and the knowledge economy; we will seek to demonstrate through this work that the patent has a central role in the process of innovation and economic growth.

We will also demonstrate that there is a circular relationship between knowledge, technology, and Patent: knowledge that turns into technology and technology that generates a patent, which in turn will become a source that will feed the knowledge that will lead to technologies and so on as well. In fact we are going to see that in developed countries, innovation is an engine of economic growth, and that in emerging countries innovation gives access to innovative technology and in certain situations an inexpensive technology transfer.

Patents can play the role of policy instruments for promoting economic development, and how developed and developing countries use patent systems, each in its own way. The debate concerning the economic principles applicable to patents is very old and dates back at least a hundred years.

On the other hand, patent information plays an undeniable role in economic development for developing countries, which in certain cases can access technology free of charge, for example by using the territorial aspect of patents (i.e. for a given country if the patent is not protected there, the industrial exploitation of the patent in this country is completely legal), these countries can also through this information find potential partners to for purposes of licensing and technology transfer.

\section{LITERATURE REVIEW}

In 1942 Schumpeter was one of the pioneers to demonstrate the relationship between innovation and development, his ideas constitute the most recognized theory on the role of technological change in the growth of the economy. This theory of innovation was based on Schumpeter's definition of "entrepreneur", meaning a person (or group of people) that must make business decisions that will lead to the introduction of new products, processes and systems or the opening of new markets and new sources of supply. Schumpeter believed that innovative entrepreneurship was more a manifestation of will than an intellectual act, and that the incredible dynamism of society was explained by leadership that created values.

Schumpeter mainly focused on the most radical innovations and in a way placed less importance on invention and dissemination.

However, It cannot be overlooked, that by focusing on major innovations, those opening new paths, Schumpeter forgot that technological change stems from a continuous process of research and gradual accumulation of knowledge, where small innovations are often as important as the most revolutionary discoveries.

Protection by different forms of intellectual property automatically generates a spirit of emulation and creativity, thus, the economist-historian Douglass North has shown that the expansion of innovations and sustained growth are dependent on the existence of an intellectual property rights system.

The objective of a patent system is to orient innovators towards qualitative improvements lying in the middle area around the optimal solution.

Michel and Nyssenm as part of an endogenous growth model with the development of new products, introduced a limited patent life as part of a Grossman and Helpman variety model. They have shown that increasing the life of patents increases the profitability of a given research and development project, but also decreases the knowledge externalities that play a crucial role in the growth process. Thus, manipulating the life of patents was, in a second-tier analysis, a means of influencing the appropriability of knowledge to promote growth.

The patent system can play an important role in disseminating new ideas; where the information contained in patents ensures the speed of access of researchers to new knowledge. 


\section{RELATIONSHIP BETWEEN ECONOMIC GROWTH AND PATENT FILING}

In fact, a simple way to do this is to seek to find a relationship between the variable that measures economic growth, namely the Gross Domestic Product and the number and patents filed.

All patent Systems that have been in place for several decades have sought to stimulate innovation to encourage economic development.

By granting a right of exclusivity limited in time and space, the public authorities give the possibility to inventors to recover the money invested in research and development, this protection also seeks to encourage investment for the commercialization of inventions, so that the public can reap the benefits of innovation. The publication of patent applications and granted patents enriches the literature and allows the circulation of knowledge through patent information.

To protect by intellectual property rights from technological inventions, the public authorities have set up protection systems, the fact of establishing this system encourages creativity and invention and therefore the development of new technologies which is corollary to the economic development and growth.

Many countries have recognized the importance of innovation in development and are seeking to reap the economic and social benefits of establishing a patent system

Developing the resources and infrastructure of these countries and their ability to benefit from the rapid growth of intellectual property as a valuable economic asset in the global economy remains an urgent concern.

The protection of industrial property by patents is intended to encourage economic agents to invest more in research and development.

On a theoretical level, the establishment of a patent system has a double objective: to encourage firms to produce new knowledge and to ensure the dissemination of information.

The patent can be an intervention tool in economic policy to encourage innovation for the benefit of growth. In fact to support growth and make it endogenous the patent can play the role of dissemination of knowledge, the counterpart for the granting of a Patent.

The Patent is an intellectual property title issued by the state for the protection of an invention or innovation. For an invention to be Patentable, it must meet 3 conditions:

Industrially applicable

Novelty

non obviousness

Patents for invention are issued for a period of 20 years, during which the fees payable to keep them in force must be paid each year following the year of grant.

\section{THE SITUATION IN MOROCCO}

Patents are expected to play an increasingly important role in the allocation of technology worldwide: they will set the conditions under which ideas and technologies can circulate between countries. Access to patents will therefore be a necessary condition for good access to global knowledge and the possibility of selling one's inventions globally. However, it appears that access to patents through economic location: the promotion of public research as well as the technological connectivity of SMEs require proximity to operators. Patent funds are powerful instruments of allocative efficiency but also of rent extraction; their use can be both offensive, in the service of long-term national interests, and technology protector.

In Morocco, the top 3 of large foreign patents applicants is represented in the Figure 1 At the top of the ranking, Americans

applicants with $20 \%$ of the total number of patent applications of foreign origin, French deposits come in second place with a share of $8.4 \%$, followed by those from Germany with a share of $8 \%$. 
Figure 1. Evolution of foreign patent filings for the 10 main filing countries.

\begin{tabular}{|c|c|c|}
\hline & $\begin{array}{c}\text { Filed } \\
\text { patents in } \\
\mathbf{2 0 1 8}\end{array}$ & Percentage \\
\hline U.S.A & 470 & $20 \%$ \\
\hline France & 195 & $8 \%$ \\
\hline Germany & 189 & $8 \%$ \\
\hline Swiss & 119 & $5 \%$ \\
\hline Italy & 99 & $4 \%$ \\
\hline Spain & 98 & $4 \%$ \\
\hline U.K & 74 & $3 \%$ \\
\hline Belgium & 73 & $3 \%$ \\
\hline Japan & 65 & $3 \%$ \\
\hline Denmark & 49 & $2 \%$ \\
\hline
\end{tabular}

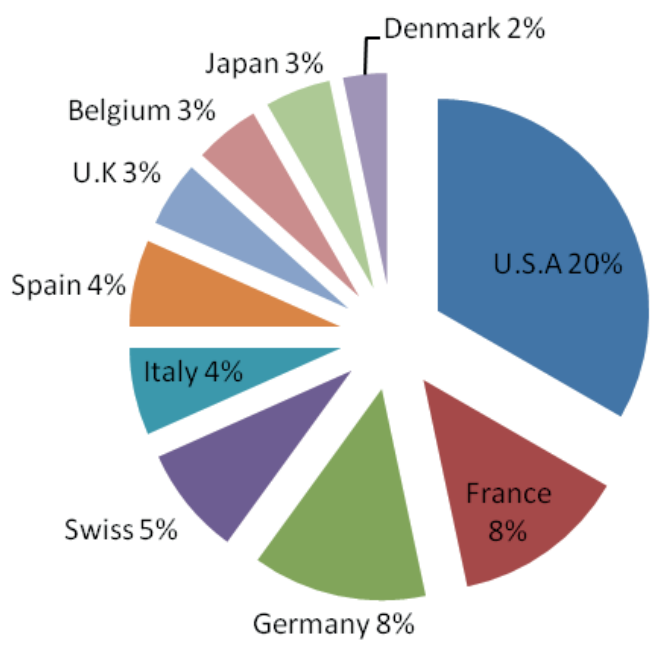

It turns out that these same countries, ranked in the top ten of patent applicants, are the same ones that participate most in the creation of wealth at the national level and value at the level of the GDP. On the other hand, the Pharmacy, Biotechnology and Chemistry sectors represent the major part of patents filed by technological field Figure 2.

The Pharmacy, Biotechnology and Chemistry sectors are also the basic sectors which have provided the Moroccan economy with increased growth in recent years.

This also represents an argument in favor of the link between innovation and economic growth.

Figure 2. Distribution of granted patents by technological field

\begin{tabular}{|c|c|}
\hline Technological field & Percentage \\
\hline $\begin{array}{c}\text { Pharmacy, } \\
\text { Biotechnology and } \\
\text { Chemistry }\end{array}$ & $65 \%$ \\
\hline $\begin{array}{c}\text { Mechanical, Energy, } \\
\text { Green technology }\end{array}$ & $18 \%$ \\
\hline $\begin{array}{c}\text { Electricity, Electronics, } \\
\text { Telecom and I.T }\end{array}$ & $17 \%$ \\
\hline
\end{tabular}

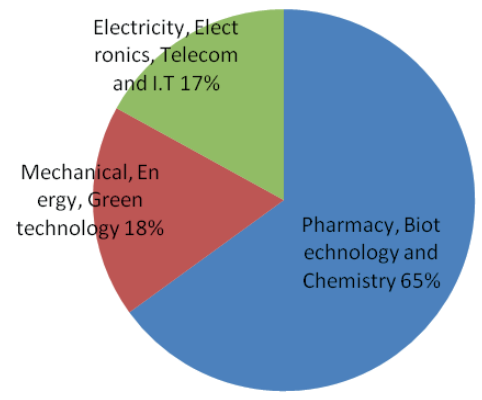

It should be noted that $85 \%$ of Moroccan patent filings are divided between universities and individual inventors, which is a weakness in the Moroccan innovation system because companies do not do Research Development enough.

It is important to point out here that it is essentially companies that are the real engines of growth and wealth creation, and for these companies to be successful they must innovate. 
Figure 3. Distribution of Moroccan patent applications by type of applicant

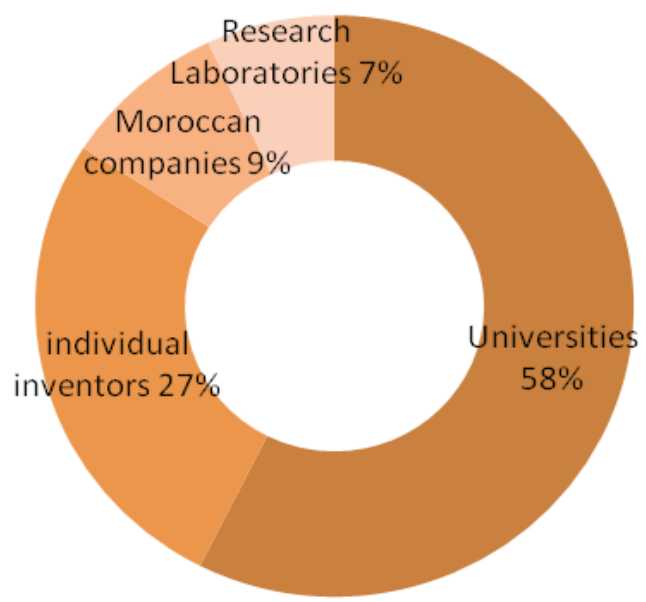

\section{MARKET VALUE OF PATENTS}

The difficulties encountered in the development of patent markets are significant: how to estimate the value of patents, and therefore the price of transactions? How can we match offers and requests, all of which are extremely specific?

Information from sellers and buyers, a necessary condition for contracts to be possible?

The development of market mechanisms to allocate patents can only be done if the value of patents can be determined by agents and implemented in transactions. The difficulties from this point of view are great, and uncertainty about the value of a patent can be on two levels:

It can first affect the future state of technologies and markets when the law is valued economically. Uncertainty then concerns the use of the patent by its holder: the same patent can have a very different value depending on who uses it.

Technical knowledge (innovations) extracted from patents is an intangible asset which is difficult to assess.

The patent is not always a global indicator of all the technological knowledge produced, since a considerable number of technological know-how remains in the form of business secrets or sometimes the technology is published in scientific articles.

The propensity to file patents varies according to the inventors and according to the countries, if the patent is a quantitative indicator of technologies, the qualitative aspect can be detected only from the moments when the patent is industrialized or marketed on a market.

Some researchers have been able to demonstrate that a $10 \%$ increase in patent filings generates $4 \%$ growth rate.

There is a circular relationship between knowledge, technology, Patent: the knowledge that turns into technology and the technology that generates a patent and which in turn will become a source that will feed the knowledge that will lead to technologies and so on so.

The patent is therefore an engine of innovation. The patent can be, if used wisely, an economic policy instrument to encourage investment in research and development. More patents give more innovations and therefore more patents and so on.

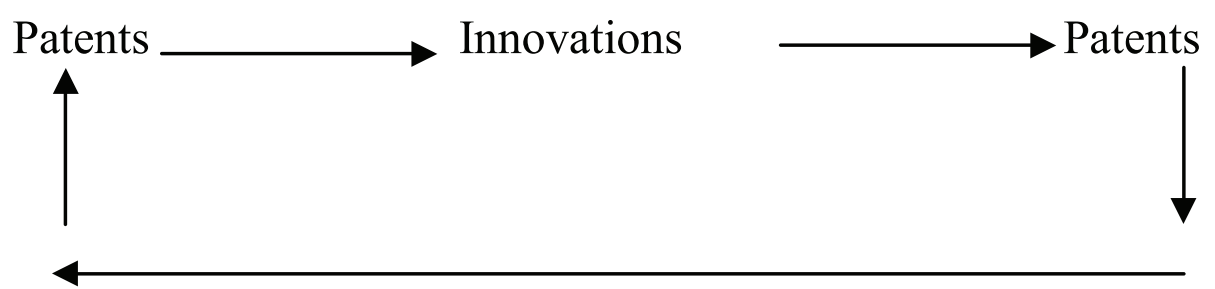


It should be taken into account that some patents find their industrial applications only after a delay of time.

Two conclusions therefore:

The patent does not represent the totality of technical knowledge, since a good part of these technologies remain confined in the form of professional secrecy, the patent does not represent the qualitative value of knowledge either because only part of the existing knowledge gives rise to patents.

The second conclusion is specific to developing countries, the innovation climates in these countries, are hampered by the weakness of the key elements of knowledge. This weakness of the research system and of national inventors is essentially due to the virtual absence of the private sector in the R\&D sphere. In these countries only $9 \%$ of R\&D spending comes from private funds, the rest is from public sources (91\%). Also, the ratio of expenditure on R\&D to GDP represents less than $1 \%$, which does not favor technological modernization and, therefore, the obtaining of patents.

The patent is a vector of economic growth through the promotion of innovation.

Figure 4. Circular relationship between knowledge, technology

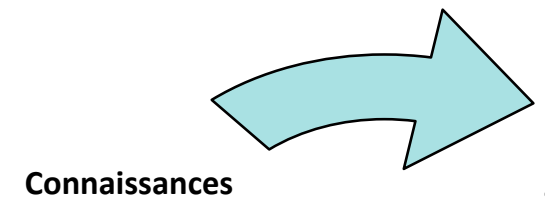

\section{Technologies}

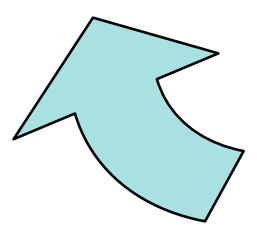

Brevets

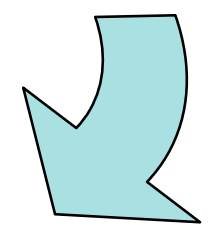

Numerous studies have shown that intellectual property encourages and boosts foreign direct investment. India, for example, has experienced a continuous strong increase in foreign direct investment since a reform of the patent and trademark system was undertaken in the early 1990s, similarly, in Brazil the increase in foreign direct investment has was even more dramatic following the adoption in 1996 of a new industrial property law. Today, the propensity of companies to patent their inventions has increased worldwide. The upward trend in patent applications is particularly marked in Japan, the United States and Europe. In Japan, it took 95 years to reach the first million patents issued and only 15 years to reach the second million.

Today, experts say, "intellectual property is one of the most valuable, if not the most critical, asset in business operations, whether it's intellectual property license agreements, joint ventures , manufacturing, purchasing or distribution, or mergers or acquisitions ". Licenses to use patents, copyrights and trademarks are often associated with transfers of know-how as part of the training and are an increasingly important element in these operations.

Extremely profitable Patents can be used to stimulate economic development in different ways. First, patent information facilitates technology transfer and foreign direct investment.

The patents then encourage research \& development in universities and research centers. They also play a catalytic role in the creation of new technologies and businesses.

Patents effectively contribute to the creation of new technologies and industries. Biotechnology is an example of a new technology, which without the patent system could not have developed. Licensing intellectual property can be extremely profitable. IBM made $\$ 1.7$ billion in revenue 
from patent licensing in the year 2000 alone. Texas Instruments, for its part, made $\$ 500$ million. Global revenues from patent licensing rose from a total of $\$ 15$ billion in 1990 to $\$ 110$ billion ten years later. "These astronomical figures should not suggest that technology licensing is a practice reserved for large multinational companies or the most highly rated research institutes. An SME holding patents can participate in this type of commercial relationship which is enhanced by the use of patents. On the other hand, "an SME without patents must rely on the time factor to reap the benefits of an advantage, better service or other elements. This applies to both advanced and developing countries. "Same pattern on the brand side. These occupy a strategic place in terms of marketing within the various companies. Studies have shown that the ability to retain customers is just as income generating as the ability to attract new ones. Brands also allow their owners to increase their profitability, to face unfair competition, to increase and maintain their market share. Other advantages for the owners, to collect royalties by conceding the use of their brands under license, to establish partnerships and strategic alliances.

It should also be noted that some authors have also mentioned an inhibiting effect on intellectual property rights

\section{CONCLUSION}

Our work focuses on the role of patents in particular and the different forms of Intellectual property on economic growth and development. We have found that patents and their applications are important for economic growth.

The patent is not always a global indicator of all the technological knowledge produced, since a considerable number of technological know-how remains in the form of business secrets or sometimes the technology is published in scientific articles.

There is a circular relationship between knowledge, technology, Patent: the knowledge that turns into technology and the technology that generates a patent and which in turn will become a source that will feed the knowledge that will lead to technologies and so on so.

The patent is therefore an engine of innovation. The patent can be, if used wisely, an economic policy instrument to encourage investment in research and development. More patents lead to more innovations and vice versa. The patent is a vector of economic growth through the promotion of innovation. 


\section{REFERENCES}

Technology and economic growth P. Hanel and G. Niosi interuniversity science and technology research center, Canada

J. Schumpeter, "Theory of economic evolution. Research on profit, credit, interest and the cycle of conjuncture ", 1942. French translation (1983), Dalloz, Paris

J. Nyssen, "The Endogenous Growth Model with Microeconomics of Innovation", Doctoral Thesis in Economic Sciences, University of the Mediterranean Aix Marseille II, 1995.

G.M. Grossman et E. Helpman,"Quality Ladder in the Theory of Growth", Review of Economic Studies, Vol. 58, pp. 43-61,1991.

D. North, "Institutions, Institutional Change and Economic Performance", Cambridge University Press, 1990.

Henri Dou et Xie Hongxia "The role of patent information in the development of innovation in smes - a focus on chinese patent" Revue internationale d'intelligence économique 2012/2 Vol 4 | page 187 .

A. MISBAHI "How intellectual property drives growth economic"Moroccan Journal the Economist Edition N $\mathrm{N}^{\circ}: 1257$ April 262018

Annual report of the Moroccan office of industrial and commercial property 2018

World Intellectual Property Organization Report 2017 